\title{
A IMPORTÂNCIA DA GESTÃO DA INFORMAÇÃO COMO UMA ATIVIDADE DO PROFISSIONAL DA INFORMAÇÃO NA ÁREA DA SAÚDE: PANORAMAS BIBLIOGRÁFICOS
}

THE IMPORTANCE OF INFORMATION MANAGEMENT AS A PROFESSIONAL ACTIVITY OF INFORMATION IN THE HEALTH AREA: BIBLIOGRAPHIC PANORAMAS

'Beatriz Rosa Pinheiro dos Santos

${ }^{2}$ Camila de Biaggi

${ }^{3}$ leda Pelógia Martins Damian

Universidade Estadual Paulista ${ }^{1,2}$

Universidade de São Paulo ${ }^{3}$

\section{Correspondência}

Beatriz Rosa Pinheiro dos Santos

Universidade Estadual Paulista

São Paulo, SP - Brasil.

E-mail: beatriz.pinheiro@marilia.unesp.br

Submetido em: 06/09/2018

Aceito em: 26/01/2019

Publicado em: 11/02/2019

Checagem Antiplagiarismo

turnitind

JITA: HC. Archival Materials 


\section{RPBO $\begin{aligned} & \text { Revista Digital Biblioteconomia e Ciência da } \\ & \text { Informação }\end{aligned}$ PPBOI $\begin{aligned} & \text { Digital Journal of Library and Information } \\ & \text { Science }\end{aligned}$

\section{RESUMO}

As mudanças e transformações nas diversas áreas do conhecimento vêm acontecendo de maneira evidente, exigindo do profissional da informação novas funções e atividades profissionais perante o mercado de trabalho. Dentre os campos de atuação, destaca-se a área da saúde como campo científico que necessita de subsídios informacionais para assistência em saúde e para o direcionamento da equipe clínica no diagnóstico dos pacientes e na tomada de decisões. Diante disso, o objetivo da pesquisa é abordar como a gestão da informação, considerada uma atividade essencial do profissional da informação, pode contribuir para as atividades e processos decisórios no contexto da área da saúde. Para isso, realizou-se uma revisão de literatura sobre os temas abordados, a fim de traçar discussões bibliográficas ao estudo. As discussões demonstram que, a partir do momento em que as organizações contemporâneas reconhecerem o valor da informação dentro do contexto organizacional, saírem da teoria e realmente aceitarem e aplicarem esses panoramas, a chamada sociedade da informação e do conhecimento poderá se desenvolver e dar mais um passo para sua evolução. Como considerações finais, justifica-se que o profissional da informação torna-se elemento fundamental na área da saúde, capaz de causar, por meio da inserção e manutenção da Gestão da Informação, melhorias internas nas atividades e tomadas de decisão das organizações de saúde, que também refletem no aumento da qualidade dos serviços prestados a comunidade.

\section{PALAVRAS-CHAVE}

Gestão da Informação. Atuação profissional. Tomada de decisão. Profissional da informação. Organizações de saúde.

\section{ABSTRACT}

The changes and transformations in the different areas of knowledge have been happening in an evident way, demanding from the information professional new functions and professional activities in the labor market. Among the fields of action, the health area is highlighted as a scientific field that requires informational subsidies for health care and for directing the clinical team in the diagnosis of patients and in decision-making. Therefore, the objective of the research is to address how information management, considered an essential activity of the information professional, can contribute to the activities and decision processes in the context of the health area. For this, a review of the literature on the topics addressed was carried out in order to draw up bibliographical discussions of the study. The discussions demonstrate that once contemporary organizations recognize the value of information within the organizational context, move away from theory and actually accept and apply these scenarios, the so-called information and knowledge society can develop and give a further step towards its evolution. As final considerations, it is justified that the information professional becomes a fundamental element in the health area, capable of causing, through the insertion and maintenance of Information Management, internal improvements in the activities and decision-making of health organizations, which also reflect in the increase of the quality of the services provided to the community.

\section{KEYWORDS}

Information Management. Professional performance. Decision making. Informational professional. Health organizations. 


\section{RPBO $\begin{aligned} & \text { Revista Digital Biblioteconomia e Ciência da } \\ & \text { Informação }\end{aligned}$ P B B

\section{Introdução}

A sociedade da informação e do conhecimento propiciam diversas atuações e funções profissionais, algumas transformações, nos âmbitos sociais, econômicos e culturais, que com o apoio das novas Tecnologias de Informação e Comunicação (TICs), concorrem para o estabelecimento de uma competitividade cada vez maior em todos os setores da sociedade, exigindo dessa maneira, profissionais mais qualificados, com uma atuação diferenciada, inovadora, empreendedora, crítica, reflexiva, criativa, apta a realizar a organização, mediação e disseminação eficiente da informação.

Nesse cenário, encontra-se o profissional da informação, que vem sentindo os efeitos dessas inovações no que diz respeito às suas diversas atuações e funções perante os diversos ambientes informacionais. Dentre as várias áreas que este profissional atua, destaca-se a da saúde, onde irá atuar em diversas especialidades, desempenhando atividades voltadas à informação e ao conhecimento, não se restringindo a realizar somente atividades do processamento técnico, mas que sejam relacionadas à Gestão da Informação (GI), onde o profissional da informação irá coletar, selecionar, avaliar, processar, armazenar informações, bem como organizar os fluxos informacionais da instituição, proporcionando informações estratégicas para a equipe, bem como inovações tecnológicas com informações relevantes para subsidiar os profissionais da área da saúde a tomarem as melhores decisões quanto a tratamentos, terapias e o diagnóstico do paciente. Essas informações necessitam ser gerenciadas de maneira correta, pois envolvem diretamente os pacientes, a desinformação ou uma informação mal estruturada pode resultar em condutas inadequadas e prejudiciais aos mesmos.

Sendo assim, torna-se necessário que a formação desse profissional contemple essas novas atuações, atingindo um ambiente profissional não tradicional, possibilitando condições fundamentais para que as equipes médicas atuem com mais eficiência, propiciando maior consistência para a resolução dos diversos diagnósticos. Nessa perspectiva, a GI abrange o conceito de translação do conhecimento crítico e a avaliação da informação científica que cerca os vários profissionais da área da saúde, inclusive o profissional da informação que atua nesta área, porquanto integra a equipe e ajuda-os na atuação de diversas atividades.

Desse modo, evidencia-se a importância desse profissional à sociedade, a partir das atividades executadas para a eficiência das organizações da área da saúde, uma vez que a informação é essencial para fornecer aportes às equipes médicas. $\mathrm{O}$ profissional da informação que trabalha com informações direcionadas a uma instituição especializada na área da saúde, precisa se adequar ao seu ambiente de trabalho, buscando compreender além da estrutura organizacional da instituição, a organização da informação dessa área e as demandas de seus usuários, para poder satisfazer as suas necessidades.

v.17

$1-17$

e019013
2019 


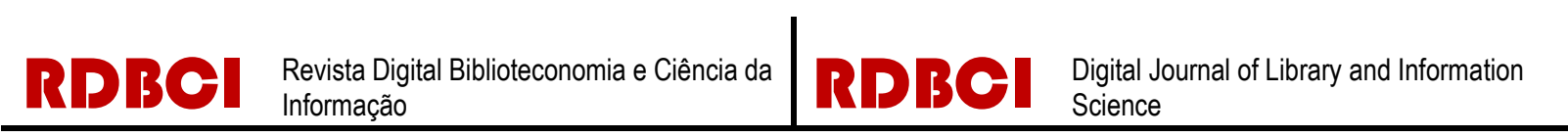

Assim, o estudo se justifica por enriquecer as discussões sobre a GI como uma atividade fundamental que o profissional da informação realiza para a tomada de decisões assertivas na área da saúde, como também consolidar sua função social nesse contexto, propiciando ambientes informacionais e de conhecimento em saúde, de modo que atenda eficientemente os diferentes públicos dessa ambiência, sejam médicos, enfermeiros, assistentes sociais e especialistas em geral, que necessitam desses elementos para sua ação efetiva junto ao paciente. Além disso, também contribui para a quebra de paradigma relacionado ao campo tradicional de atuação do profissional da informação, que ainda enfrenta algumas lacunas no que se refere ao ato de atuar em outros contextos organizacionais.

Assim, o objetivo da pesquisa consiste em abordar a GI como atividade essencial do profissional da informação, que pode contribuir para as atividades e tomada de decisões no contexto da área da saúde. Para isso, realizou-se uma revisão bibliográfica para a construção do corpo teórico que fundamenta as discussões sobre a importância da gestão da informação na área da saúde como atividade do profissional da informação, especialmente $o$ bibliotecário, sobre os temas abordados.

\section{Gestão da Informação na Área da Saúde}

Inseridos em ambientes de prestação de serviços voltados à saúde do ser humano, os profissionais, sujeitos fundamentais nesses ambientes, são cobrados diariamente por uma série de fatores que agregam comprometimento e habilidades perante os processos de trabalho que desenvolvem no dia a dia.

Esses fatores estão ligados à comunicação interpessoal, ao uso das TICs e, no geral, ao contato direto e diário com a informação. Portanto, pode-se afirmar que esses profissionais necessitam de informação eficiente e adequada para as diversas nuances e situações pertinentes a esses ambientes organizacionais e que o caminho para o acesso dessas informações está no processo da sua gestão, ou seja, sem a execução das etapas relacionadas à gestão da informação, dificilmente esses profissionais terão informação de valor para suas atividades e tomadas de decisões.

Tradicionalmente, a gestão da informação é considerada um conjunto de atividades que visam obter necessidades informacionais, mapear fluxos formais de informação, prospectar, coletar, filtrar, monitorar e disseminar informação, no intuito de conseguir utilizála nas tarefas diárias e nos processos decisórios dos ambientes organizacionais. (VALENTIM, 2008). 


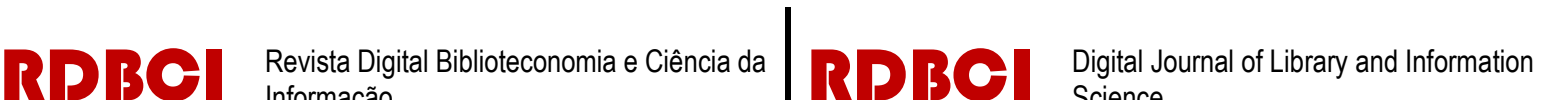

De acordo com Chaves (2013), a gestão da informação está dividida entre os componentes de organização, armazenamento e recuperação da informação, onde a etapa de organizar é responsável por reunir informações e ordená-las a fim de disponibilizá-la mais facilmente, enquanto que a etapa de armazenamento corresponde ao ato de colocar a informação em locais seguros, onde ela não será perdida, e por último, na etapa de recuperação, as informações necessárias são acessadas e utilizadas para tomada de decisão.

Enquanto que, para Ponjuán Dante (2007), a GI é considerada um processo no qual se utilizam os recursos básicos de uma organização, para o gerenciamento e manuseio da informação dentro do ambiente organizacional. Oliveira e Bertucci (2003) pontuam que a GI possui objetivos de promover a eficiência organizacional, suprindo demandas de necessidade de informação, planejando políticas voltadas ao tratamento da informação, desenvolvendo e trabalhando diariamente em sistemas e serviços de informação, otimizando os fluxos informacionais e controlando as TICs presentes no ambiente organizacional.

Dessa maneira, para se alcançar esses objetivos e colocar em prática os processos da GI, é extremamente necessário propiciar o desenvolvimento de uma cultura organizacional que incentive a realização dessas práticas pelos profissionais que atuam nesses ambientes organizacionais, especialmente pelos profissionais da informação. Esses ambientes organizacionais expressos no texto estão relacionados ao contexto da saúde, que deve portarse de profissionais que realizem com afinco as atividades voltadas à gestão da informação, considerando as inúmeras variáveis informacionais que estão conectadas ao paciente e seu contexto de vida.

Além disso, para Borges (2014), uma gestão da informação somente será eficaz se a organização estabelecer políticas que propiciem o fornecimento de informações efetivas e com possibilidade de serem acessadas de forma apropriada. E para que essa política seja colocada em prática, o gestor da organização deverá incluir em sua cultura a valorização de um profissional da informação, a fim de inserí-lo nesse contexto organizacional, como membro importante da equipe de trabalho.

Na sociedade da informação, o maior objetivo está em disponibilizar informação para todas as pessoas em qualquer lugar e em qualquer formato, proporcionando o acesso a todos, diminuindo a exclusão social e informacional da sociedade. (BARRETO, 2002). Isso porque, de acordo com Tabosa et al (2013), a informação está presente na vida de muitas pessoas, pois é capaz de fornecer meios de interpretação e compreensão de tudo o que acontece no mundo.

Ademais, para Barreto (2002) e Tabosa et al (2013), é difícil falar de informação, sem abordar o papel da comunicação como um processo fundamental na criação de relações 


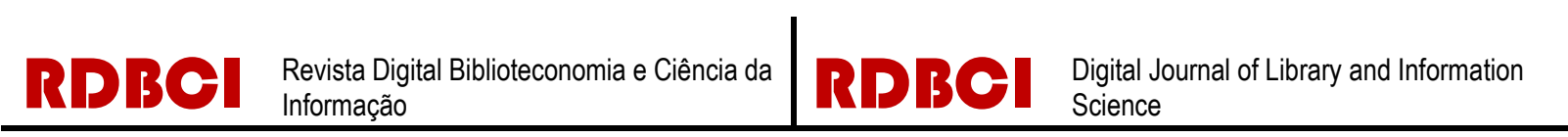

interpessoais, que na área da saúde é muito importante de serem desenvolvidas, a fim de incentivar a cooperação entre os profissionais e os pacientes. Nessa área, informação é utilizada para reduzir incertezas no planejamento e na execução de ações e cuidados que possibilitem aos pacientes melhorias na qualidade de vida. (TABOSA et al, 2013).

Todavia, Marchiori (2002) e Carvalho (2009) corroboram que, embora as organizações de saúde produzam um grande volume de informação, a sua utilização na melhoria dos processos de gestão ainda é ineficiente. Por isso, Borges (2014) acentua a relevância da gestão da informação nessas organizações, como instrumento de tomada de decisão, elaboração de medidas para a prestação de serviços, criação de estratégias e novas atividades no ambiente organizacional que possibilitem o acesso e a construção do conhecimento pelos profissionais.

A gestão da informação no ambiente da área da saúde, ou seja, em hospitais e clinicas tem a função de buscar a melhoria continua para o acesso, compartilhamento e uso da informação. A informação relaciona-se aos exames de diagnóstico, às consultas médicas, ao receituário prescrito, às informações financeiras relativas às internações, enfim uma gama de informações que possuem diferentes objetivos e, portanto, diferentes tipos de usos.

Nesse sentido, de acordo com Simeão e Mendonça (2007), a gestão da informação em saúde é essencial para a melhoria dos serviços que são ofertados aos pacientes, pois é um processo que inclui a interação entre diversos sujeitos, internos ou externos, em prol de organizar e utilizar informação para diferentes atividades e situações que envolvem o ser humano.

Carvalho (2004) e Moraes e Gómez (2007) afirmam que a informação em saúde surge no seio das práticas relativas ao processo, tratamento e oferta dos serviços de saúde, e que assim, as informações decorrentes dessas situações ganham visibilidade nos contextos sociais. Concomitantemente, ao tocar nesse assunto é importante não se esquecer de abordar as TICS presentes nos ambientes organizacionais contemporâneos e ferramentas importantes para o processo da GI. Serafim (2005) afirma que o uso das TICS no contexto hospitalar é importante para a utilização e acesso de informações e indicadores do hospital, o que auxilia na criação de planos estratégicos que subsidiem os processos decisórios. Assim, Pinochet, Lopes e Silva (2014) afirmam que em um ambiente hospitalar, as TICS podem possibilitar melhorias na gestão da organização como a redução de custos e o aumento de controle de situações decisivas no tratamento do paciente. Para os autores, a implantação dessas tecnologias pode propiciar o desenvolvimento de um atendimento mais qualitativo ao paciente.

Dessa maneira, o papel da GI está na criação de condições para interação dos (c) RDBCl: Rev. Digit. Bibliotecon. Cienc. Inf. 1 Campinas, SP v.17 $1-17$ e019013 2019 


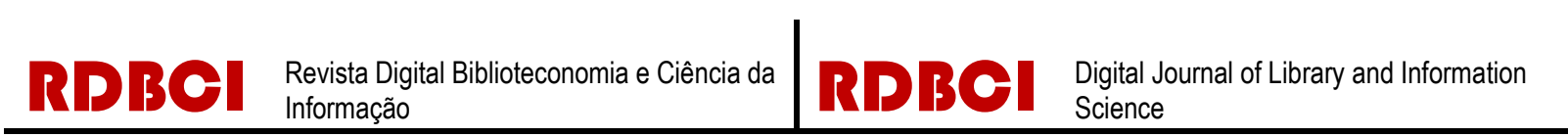

profissionais presentes no ambiente organizacional, possibilitando relações diretas que resultam em um ambiente sinérgico e eficiente em suas funções. Disto, decorre a importância de acontecer uma parceria e uma relação entre os profissionais da informação e profissionais da saúde, que, ao lidar com determinado caso e utilizar determinadas informações que são coerentes com esse caso, alcançando efetividade em seus resultados, poderá comunicar ao profissional da informação todo o contexto e os acontecimentos evolutivos do seu caso, a fim de que esse profissional possa sistematizá-los, e assim, disponibilizar e divulgar essas informações a outros profissionais. Além disso, esse processo pode ser um fator potente para a construção de conhecimento entre todos os profissionais do ambiente organizacional.

Por fim, considerando o fato de que a Ciência da Informação (CI) é uma ciência interdisciplinar, que envolve diversos profissionais de diferentes áreas do conhecimento, em prol do estudo da informação que se encontra perante os diversos ambientes da sociedade (FREIRE, 2001; CAPURRO, 2003), é possível dizer que se torna muito importante que essa ciência trabalhe também e especialmente a informação nos contextos da saúde, construindo elos interdisciplinares efetivos com essa área de conhecimento. Para tanto, é relevante conhecer os sujeitos que estão inseridos na CI, a fim de discutir a importância das suas características e se inserirem no contexto dessa área.

\section{Atuação do Profissional da Informação na Área da Saúde}

Para o contexto deste trabalho, foram abordadas questões relativas às possibilidades de atuação do profissional da informação na área da saúde, mais especificamente o bibliotecário, enfatizando a gestão da informação como uma atividade fundamental para subsidiar a tomada de decisões dos profissionais clínicos, consequentemente atendendo suas necessidades informacionais.

O profissional bibliotecário precisa buscar aperfeiçoamento e atualizações constantemente, desenvolvendo competências e habilidades fundamentais que o mercado e a sociedade exigem, tendo consciência de seu papel como profissional e suas devidas atividades informacionais visando uma maior participação na denominada sociedade da informação. Para isso, é importante destacar que a atuação do bibliotecário vem passando por várias transformações no que diz respeito aos seus campos de atuação, pois ele subsidia todas as práticas dos profissionais da área da saúde, pois possibilita que as informações relevantes e necessárias ao cotidiano médico-hospitalar sejam acessadas, compartilhadas e apropriadas em diferentes momentos, melhorando sensivelmente a atuação clínica.

Banks et al. (2005) destaca que o bibliotecário que atua no campo da saúde, pode minimizar a dificuldade que os usuários possuem em identificar e encontrar a informação

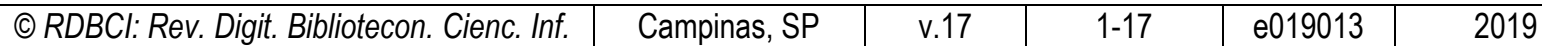




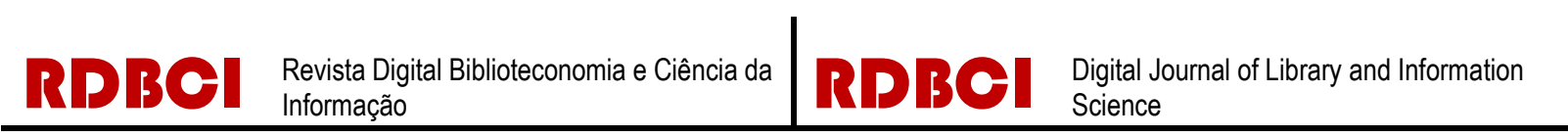

correta, avaliar e usar corretamente as fontes de informação. O bibliotecário é responsável por desenvolver um conjunto de estratégias informacionais, visando que a equipe clínica possa apropriar, construir e compartilhar informação e conhecimento, bem como estabelecer fluxos formais e informais que assegurem que a informação 'certa' seja acessada no 'tempo' e 'formato' adequados, auxiliando na geração de ideias, na solução de problemas e na tomada de decisão, planejando e estabelecendo um fluxo informacional eficiente, abrangendo desde a gestão da informação relacionada à administração hospitalar, até as áreas de diagnóstico, tratamento e reabilitação.

Os espaços de atuação do bibliotecário são reconhecidos principalmente pelas instituições públicas, principalmente universidades, escolas, centros culturais e os arquivos. Dentro de ambientes voltados para a área da saúde, a atuação que o bibliotecário realiza frente às instituições de ensino ou em hospitais torna-se muito importante, uma vez que pressupõe atividades de busca em sistemas de informação, análise e negociação de questões e formulação de estratégias que indiquem o êxito da busca, bem como o auxílio a encontrar materiais relevantes de estudo e pesquisa para os profissionais clínicos, estudantes e professores, tornando as bibliotecas hospitalares um espaço ativo para prestação de serviços.

Atuando fora das bibliotecas médicas, pode-se ampliar o papel do bibliotecário para além da busca por informações, possibilitando o seu envolvimento com a seleção e avaliação crítica da literatura, atuando nos moldes da 'Biblioteconomia Clínica', na qual o bibliotecário é considerado parte integrante das equipes multidisciplinares de saúde. Autores como Coutinho (2004), e Marasciulo e Nassar (2004) alertam que o aumento exponencial do volume e da complexidade da literatura médica impõe a necessidade de melhorar a análise e a síntese das informações, no que tange a sua qualidade [fidedignidade, consistência, relevância e atualidade], pois as tecnologias de informação e comunicação tornam, cada vez mais, acessíveis a enorme quantidade de pesquisas científicas.

Desta forma, a área da saúde constitui-se um conglomerado de informações, onde há uma colaboração entre as funções realizadas pelo bibliotecário e as atividades desenvolvidas pelos profissionais da saúde, em busca do melhor atendimento às demandas dos pacientes. $\mathrm{O}$ bibliotecário clínico é conhecido nos Estados Unidos e em alguns países da Europa como o profissional que atua fora do espaço das bibliotecas, como parte integrante das equipes multiprofissionais de saúde de hospitais e clínicas. A atuação deste profissional consiste em fornecer, aos médicos e aos demais membros das equipes, informações que lhes permitam a melhor decisão relacionada ao problema de saúde do paciente, fundamentada na melhor evidência científica disponível, contribuindo para o melhor atendimento à sociedade.

A atuação do bibliotecário é concentrada na recuperação da informação, segundo as necessidades dos usuários, exercendo um papel de mediador da informação, e não apenas de 


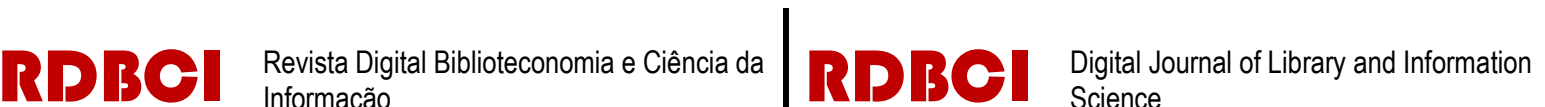

disseminador. No hospital ou clínica, o bibliotecário clínico é o profissional que medeia a informação ao usuário, antecipa suas questões e busca entregar ao profissional da saúde a informação adequada, o que segundo Lipscomb (2000), confirma o objetivo da Biblioteconomia Clínica, qual seja, a de reforçar a missão da própria Biblioteconomia que, é tornar a informação relevante e disponível no momento em que é solicitada.

Além de atuar em bibliotecas hospitalares e como um bibliotecário clínico, este profissional pode ser um informacionista, trabalhando entre as equipes médicas e a informação especializada, selecionada, prospectada, organizada, atualizada, buscando as melhores evidências científicas a serem tratadas pelo corpo clínico, analisando os dados e aplicando de acordo com os casos.

Para Davidoff e Florance (2000), bem como para Plutchak (2000), no âmbito dos Estados Unidos, o termo 'informacionista' pode ser usado para o bibliotecário clínico, por estar exposto a situações clínicas e possuir conhecimentos de estatística e epidemiologia.

O informacionista, diferente do bibliotecário clínico, realiza análises da informação, atividade própria dos especialistas em suas respectivas especialidades. O bibliotecário clínico concentra-se em prospectar informações sobre um determinado caso, à medida que otimiza o compartilhamento da informação adequada às necessidades informacionais da equipe médica. No entanto, como afirma Andalia (2002), a análise da informação é parte constituinte das Ciências da Informação, mas no campo das Ciências Médicas falta a figura desse profissional, cuja tarefa principal é determinar a validade dos conhecimentos que subsidiam a prática clínica, a partir de estudos realizados em uma área específica.

Beraquet et al. (2005) realizaram um estudo junto aos profissionais da informação que atuam na área da saúde e identificaram que, além de saber trabalhar em equipes multidisciplinares, onde o profissional bibliotecário a partir da sua formação especializada e qualificada possui um conjunto de domínios de conhecimentos voltados à: informática, redes, bases de dados e demais fontes de informação em saúde; noções de saúde pública, os mesmos devem ter competência de estabelecer boa relação interpessoal com diferentes profissionais e competências voltadas a gestão de projetos em que são fundamentais para que o bibliotecário da área da saúde possa exercer sua função com destreza e eficiência. Pelo exposto, o bibliotecário que atua na área da saúde ao longo dos anos, pode ser chamado de bibliotecário hospitalar, bibliotecário médico, bibliotecário biomédico, bibliotecário clínico ou informacionista. Assim, independente da denominação que receba, o mais importante é perceber a evolução com relação às diversas praticas profissionais que o bibliotecário possa vir atuar, sendo um parceiro importante para as equipes médicas, em busca do melhor atendimento à saúde da população. A qualidade do trabalho do bibliotecário incidirá diretamente na atuação da equipe clínica, bem como propiciará maior integração à equipe 
RDBCI

multiprofissional, garantindo o direito de acesso e viabilizando dados e informações de qualidade para a pesquisa e o ensino em saúde. Por isso, esse profissional em bibliotecas tradicionais de hospitais universitários, bem como na própria estrutura hierárquica de um hospital, dentro de um setor especializado e voltado à gestão da informação.

Dessa maneira, a atuação do bibliotecário vem passando por várias transformações, tanto no que se refere a sua postura profissional bem como por mudanças no que diz respeito aos campos de atuação, possuindo atualmente grande potencial e diversidade para exercer suas funções e responsabilidades profissionais, utilizando seu conhecimento para acessar, prospectar, selecionar, analisar, sistematizar, organizar e disseminar a informação para assim, atender as necessidades informacionais da equipe multiprofissional. A escassez de tempo desses profissionais, e abaixa familiaridade com as bases de dados são aspectos indicados na literatura como razões para a ação do bibliotecário junto às equipes de saúde, contribuindo com as suas funções e atividades informacionais para a tomada de decisões assertivas, fundamentando-se nas melhores evidências científicas.

\section{Uso da Informação em Saúde para Tomada de Decisões}

Atualmente, o uso correto da informação em saúde, se tornou um insumo indispensável para qualquer atividade, considerado como recurso viabilizador de decisões assertivas. Entretanto, é necessário salientar um aspecto problemático relacionado à grande quantidade de informações, pois, muitas vezes elas não são identificadas, processadas e recuperadas de maneira correta, para solucionar um determinado problema no contexto clínico. Dessa maneira, uma das melhores formas de resolver esses problemas é extrair da imensa massa de informações, aquelas que são consistentes, íntegras, precisas, atualizadas, com valor agregado e que serão imprescindíveis para a tomada de decisão e para a resolução de alguma necessidade informacional.

Nesse sentido, o papel do bibliotecário é essencial, pois a partir de uma formação adequada e especializada, se torna capacitado para filtrar informação, organizar, analisar e disseminar para os profissionais da área da saúde, para posteriormente tomar as melhores decisões e subsidiar as equipes clínicas nos diagnósticos, tratamentos, terapias, as melhores evidências científicas, exercendo um trabalho em prol da equipe multiprofissional, compartilhando e mediando informações e contribuindo ativamente para o aumento do fluxo e da disseminação de informações. (DE BIAGGI, 2017).

Na medida em que são ampliados os espaços de atuação do bibliotecário, ampliam-se também as exigências para um profissional com novas competências, novas funções e atividades, possuindo consciência do seu papel perante a sociedade. A organização de informação na nova economia requer um novo perfil profissional que exige qualificação e

\begin{tabular}{l|l|l|l|l|l|}
\hline (c) RDBCl: Rev. Digit. Bibliotecon. Cienc. Inf. & Campinas, SP & v.17 & $1-17$ & e019013 & 2019 \\
\hline
\end{tabular}




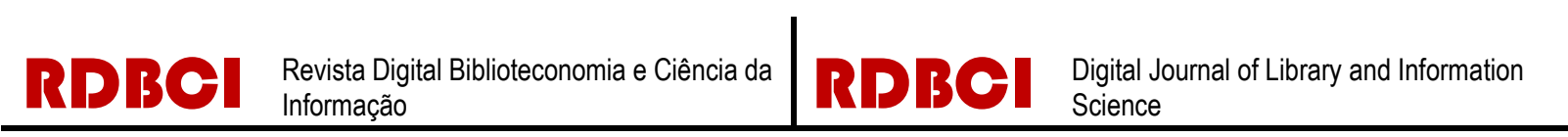

maior envolvimento emocional e social entre a equipe de trabalho, para desenvolver bem as suas tarefas. Assim, para Arruda et al. (2000, p.17), “[...] elege-se como ideal o profissional que potencialize a comunicação, a interpretação de dados, a flexibilização, a integração funcional e a geração, absorção e troca de conhecimento".

Dessa maneira, a gestão da informação na área da saúde ajuda o bibliotecário a agregar valor à informação, a fim de transforma- lá em conhecimento, apoiando assim o planejamento estratégico da instituição. Davenport (1998, p.173) compreende a gestão da informação como um "[...] conjunto estruturado de atividades que incluem o modo como as instituições obtêm, distribuem e usam a informação e conhecimento".

Todavia, o processo da GI em organizações, ainda segundo o autor supracitado, deve passar por melhorias constantes, ou seja, por aperfeiçoamentos contínuos voltados ao uso com qualidade das atividades, com abordagem total as informações que estão sendo gerenciadas e também relacionadas às pessoas que estão envolvidas nessa instituição desempenhando suas funções, administrando as informações da melhor maneira possível, consequentemente produzindo conhecimento para os profissionais que atuam nesse ambiente.

Assim, a GI possui aspectos relevantes que compreendem: busca de qualidade, produção e gestão eficiente da informação, instigar a criatividade e as devidas competências, de maneira a satisfazer os sujeitos organizacionais de uma instituição da área da saúde, proporcionando o melhor atendimento ao paciente. Uma das principais tarefas da gestão em saúde é possibilitar e garantir o acesso às pessoas e aos serviços de saúde (cobertura assistencial), com maior atenção aos grupos populacionais e prioritários.

Em síntese, a gestão em saúde é a inteligência constitutiva de um sistema de saúde mediante a definição de critérios de alocação de recursos, papéis de órgãos públicos e privados, oferta de cooperação técnica aos órgãos descentralizados, redistribuição dos gastos correntes e de investimentos e estabelecimento de mecanismos de contratos de gestão. Por conseguinte, a gestão em saúde absorve totalmente as atividades do planejamento em saúde e agrega as articulações políticas e as ações de implementação de planos.

À vista disso, a atuação do bibliotecário nas organizações de saúde está voltada à geração, mediação, processamento e uso de dados, informação e conhecimento, visando o tratamento para interagir e agregar valor ao processo de tomada de decisão (VALENTIM, 2004).

No processo de gestão da informação, a tomada de decisão exige grande responsabilidade e tem alta relevância social, pois envolve a qualidade de vida e o bem-estar das pessoas. Nesse contexto, o uso correto das informações funciona como instrumentos ou

v.17

$1-17$

e019013
2019 


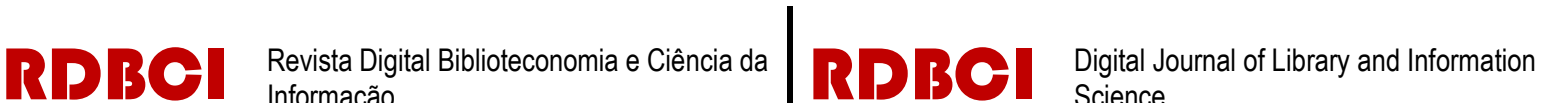

ferramentas para diminuir o grau de incertezas sobre uma determinada situação de saúde, dando suporte ao processo de tomada de decisão.

Cândido; Valentim e Contani (2005, p. 2) afirmam que

[...] as organizações devem gerenciar da informação de forma integrada, a fim de usá-la no momento da tomada de decisão; que de para assegurar sua sobrevivência, crescimento e evolução, uma organização não pode se descuidar da sinergia entre os diferentes setores bem como do compartilhamento da informação gerada internamente, visando a fluxos dinâmicos e acessíveis; de que é indispensável que sejam utilizadas ferramentas de apoio à gestão estratégica da informação, de modo que possam contribuir para a seleção e filtragem da informação mais adequada à tomada de decisão.

Dessa maneira o conceito apresentado acima, demonstra a importância do gerenciamento eficaz da informação, para melhorar as decisões a serem tomadas pelas organizações. Em vista disso, Guimarães e Évora (2004, p. 72) acrescentam que "a maneira como a informação é obtida, organizada, gravada, recuperada e posteriormente utilizada permite ao gerente atuar com mais segurança, aumentando a possibilidade de acerto na tomada de decisão". As autoras, por sua vez, não destacam ou utilizam os termos gestão e fluxo da informação, no entanto percebe-se que estão intrínsecos á sua explicação.

A tomada de decisão, segundo Oliveira (2004), é a conversão das informações analisadas em ação. $\mathrm{O}$ bibliotecário busca informações que atendam às necessidades de seu público usuário, espelhando a real situação da instituição, para que o processo decisório seja efetuado de forma eficaz, para alcançar os resultados pretendidos. Neste sentido, entende-se que as decisões precisam ser tomadas de forma ágil e corretas, pois o desempenho das organizações depende da qualidade de seu gerenciamento.

Para Drucker (1998 apud DAVENPORT; PRUSAK, 1998, p. 19), informação é definida como "[...] dados dotados de significado e propósito." Deste modo, a informação torna-se relevante quando passa a ter valor agregado, confirmando a importância da informação, fazendo-a constituir-se em subsídio essencial para a tomada de decisão. Logo, a informação passa a ser produto qualificado, precisando ser gerenciado, ou seja, prospectado, selecionado, analisado, tratado, organizado e disseminado, para que a equipe clínica possa usufruir e, a partir, da apropriação, construir conhecimento.

Assim, em todo momento profissionais da área da saúde tanto médicos como clínicos exercem o papel de tomar diversas decisões, pois esse campo de atuação envolve diferentes tipos de informações como: aquelas conservadas nos arquivos médicos, informação técnicocientífica, bases de dados referenciais (bibliografias, artigos, textos completos), informação de caráter administrativo, bem como auxiliando a equipe com relação ao paciente dando suporte a solução de algum problema ou a partir de uma necessidade de gerir questões

\begin{tabular}{l|l|l|l|l|r}
\hline (c) RDBCl: Rev. Digit. Bibliotecon. Cienc. Inf. & Campinas, SP & v.17 & $1-17$ & e019013 & 2019 \\
\hline
\end{tabular}




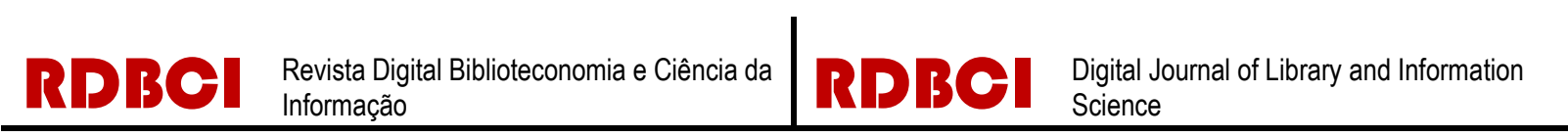

relacionadas à informação e ao conhecimento, onde se vê um maior reconhecimento oferecido ao profissional da informação que passa a ser visto como um gestor da informação (BARRETO, 2005), onde se obtém respostas rápidas e eficientes, caso isso não ocorra, todo o processo organizacional fica comprometido.

\section{Considerações Finais}

Buscou-se neste trabalho discutir a importância do processo de gestão da informação como atividade do profissional da informação, especialmente o bibliotecário, na área da saúde, bem como abordar aspectos que incentive a inserção desses profissionais nesta área, o que pode ser potencial para incentivar estudantes do curso de biblioteconomia a buscarem outros campos de atuação, fora os já tradicionais, e como consequência disso, colaborar com equipes médicas, disponibilizando informação gerenciada e de qualidade, para tomadas de decisões eficazes no cuidado ao paciente.

Muitos pesquisadores atuais afirmam o quanto a informação encontra-se presente em demasia nos mais diferentes contextos e ambientes da sociedade. E, aliás, o quanto essa informação se tornou insumo imprescindível e estratégico para a execução de atividades e processos decisórios das organizações, sejam públicas ou privadas.

No tocante em que profissionais bibliotecários são cada vez mais especializados e preparados para lidar com todo esse volume de informação, fica evidente a necessidade de esses estarem inseridos nos mais variados ambientes organizacionais, a fim de planejarem, gerenciarem e disponibilizarem informação precisa para os demais membros da equipe em que estarão inseridos. É como criar um novo departamento de produção, no qual a informação é a matéria-prima principal, e os profissionais da informação são os sujeitos organizacionais que vêm para integrarem e unir forças com os demais.

A partir do instante em que as organizações contemporâneas abrirem visão para o valor da informação dentro do contexto organizacional, saírem da teoria e realmente aceitar e aplicar esses panoramas na prática, a chamada sociedade da informação e do conhecimento poderá se desenvolver e dar mais um passo para sua evolução. O bibliotecário contemporâneo pode atuar como parte de equipes multidisciplinares, formadas por profissionais de distintas áreas do conhecimento, se envolvendo com tarefas gerenciais e de pesquisa até então pouco exploradas. Além disso, são necessárias habilidades de comunicação com outros especialistas para atender eficientemente as demandas informacionais.

Especificamente, a área da saúde consiste em um universo que lida com um montante de informação a todo o momento, desde o cadastro dos pacientes, seus perfis, características

\begin{tabular}{l|l|l|l|l|l|}
\hline (c) RDBCl: Rev. Digit. Bibliotecon. Cienc. Inf. & Campinas, SP & v.17 & $1-17$ & e019013 & 2019 \\
\hline
\end{tabular}




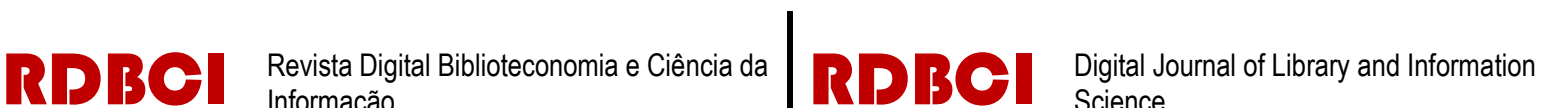

do contexto físico, psicológico e social em que vivem, suas queixas, informações para tratamento, etc. Ou seja, em todas as etapas executadas nesse ambiente, a informação está presente e requer dos profissionais que nela atuam, a capacidade de se relacionarem com o funcionamento do sistema social de uma localidade, região ou país, ou seja, com a saúde da população, influindo na maneira que diferentes disciplinas do conhecimento podem contribuir para alcançar esse objetivo.

A área da saúde como campo científico não existiria sem o subsídio de uma quantidade de informações, abrangendo o contexto administrativo hospitalar, o contexto da assistência em saúde, o contexto clínico direcionado a equipe de profissionais médicos e as evidências científicas que a equipe clínica possa acessar para diagnosticar e tomar decisões. Nessa perspectiva, o bibliotecário pode contribuir, subsidiando tanto os médicos como também os pacientes, no que tange a tomada de decisão sobre o quadro clínico dos pacientes, no intuito de proporcionar uma dinâmica informacional que atenda às demandas existentes.

E assim, essa área é imprescindível para o desenvolvimento da sociedade, o profissional da informação, ou seja, o bibliotecário torna-se elemento fundamental desse ambiente, assumindo uma função específica, assim como os demais (médicos, enfermeiros, técnicos e outros), capaz de gerenciar toda informação que circula no ambiente, criar estratégias e programas que podem auxiliar nos tratamentos e disponibilizar serviços informacionais que irão contemplar diretamente toda a equipe médica. $\mathrm{O}$ uso da informação científica relevante e de qualidade no apoio às práticas médicas, em uma sociedade da informação privilegiada é fundamental e de grande importância para garantir o sucesso do diagnóstico, prognóstico, terapia e prevenção a doenças, alicerçadas na prática conjunta da atuação do bibliotecário e da equipe clínica.

Por fim, como apoio ao desenvolvimento de pesquisas futuras, indica-se uma análise, por meio de pesquisa de campo, sobre a opinião dos gestores e equipe desses acerca da importância da gestão da informação e dos profissionais da informação se inserir nesses contextos.

\section{Referências}

ANDALIA, Rubén Cañedo. Del bibliotecario clínico al informacionista: de la gerencia de la información a la gestión del conocimiento. ACIMED, Havana, v.10, n.3, p. 11-12, jun. 2002. Disponível em: http://scielo.sld.cu/scielo.php?script=sci_arttext\&pid=S102494352002000300006\&lng=es\&nrm=iso. Acesso em: 05 ago. 2017.

ARRUDA, M. C. C.; MARTELETO, R. M.; SOUZA, D. B. Educação, trabalho e o delineamento de novos perfis profissionais: o bibliotecário em questão. Ciência da

v.17

1-17

e019013




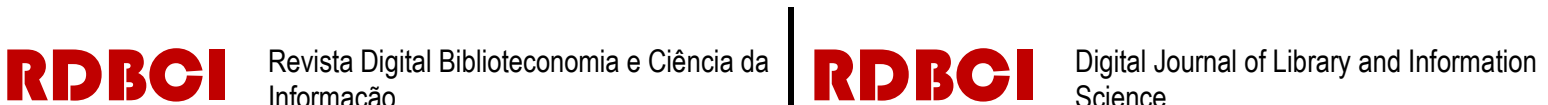

Informação, Brasília, v.29, n.3, p.14-24. 2000. Disponível em: http://www.scielo.br/pdf/ci/v29n3/a02v29n3.pdf. Acesso em: 10 jul. 2017.

BANKS, Marcus.; COGDILL, Keith.; SELDEN, Catherine.; CAHN, Marjorie. Complementary competencies: Public health and health sciences librarianship. Journal of the American Medical Association (JAMA), v.93, n.3, p.338-347, Jul. 2005. Disponível em: https://www.ncbi.nlm.nih.gov/pmc/articles/PMC1175799/. Acesso em: 02 ago. 2017.

BARRETO, Aldo de Albuquerque. A condição da informação. Perspectivas em Ciência da Informação, Belo Horizonte, v.16, n.3, p.67-74, jul./set 2002. Disponível em: http://www.scielo.br/scielo.php?script=sci_arttext\&pid=S0102-88392002000300010. Acesso em: 4 ago. 2017.

BARRETO, Angela Maria. O fator humano e o desenvolvimento de competências nas unidades de informação. Perspectiva em Ciência da Informação, Belo Horizonte, v.10, n.2, p.132-139, jul./dez., 2005. Disponível em:

http://portaldeperiodicos.eci.ufmg.br/index.php/pci/article/view/342/149. Acesso em: 6 ago. 2017.

BERAQUET, Vera Silvia Marião. et al. Delineando as competências do bibliotecário para atuar em saúde. In: ENCONTRO NACIONAL DE PESQUISA EM CIENCIA DA INFORMACAO, 6., 2005, Florianópolis. Anais... Florianópolis: UFSC, 2005. 8p. 1 CDROM

BORGES, Fabrício Quadros. Gestão da informação no sistema único de saúde. Revista de Administração FACES Journal, Belo Horizonte, v.13, n.2, p.83-98, abr./jun. 2014. Disponível em: http://www.fumec.br/revistas/facesp/article/view/2021. Acesso em: 4 ago. 2017.

CÂNDIDO, C. A; VALENTIM, M. L; CONTANI, M. L. Gestão estratégica da informação: semiótica aplicada ao processo de tomada de decisão. Data Grama Zero: Revista de Ciência da Informação, Rio de Janeiro, v. 6, n. 3, jun. 2005. Disponível em: http://basessibi.c3sl.ufpr.br/brapci/index.php/article/view/0000003073/252e5794a34943c843f $\underline{\mathrm{d} 4219154 \mathrm{~d} 1 \mathrm{ec} 9}$. Acesso em: 1 set. 2017.

CARVALHO, André Luis Bonifácio de. A Gestão da Informação em Saúde e o Município: um estudo sobre municípios que implantaram o Programa Saúde da Família e que estão integrados ao Projeto da Rede Estadual de Informação em Saúde REIS/RNIS-PB. 2004. Dissertação (Mestrado). Universidade Federal da Paraíba, João Pessoa, 2004.

CARVALHO, André Luis Bonifácio de. Informação em saúde como ferramenta estratégica para a qualificação da gestão e o fortalecimento do controle social no SUS. Tempus: Actas de Saúde Coletiva, v.3, n.3, p.16-30, jul./dez. 2009. Disponível em: http://www.tempusactas.unb.br/index.php/tempus/article/view/719/1553. Acesso em: 06 ago. 2017. 


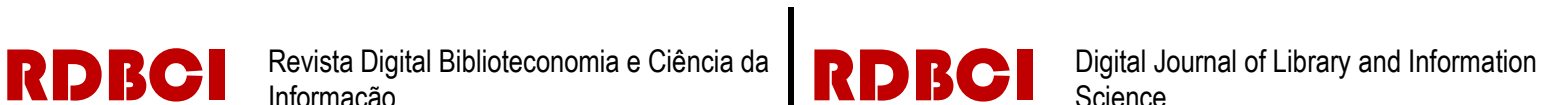

CAPURRO, Rafael. Epistemologia e ciência da informação. In: ENCONTRO NACIONAL DE PESQUISA EM CIÊNCIA DA INFORMAÇÃO, 5. Belo Horizonte, 2003. Anais... Belo Horizonte, 2003. Disponível em: http://www.capurro.de/enancibp.htm. Acesso em: 06 ago. 2017.

CHAVES, Eduardo. Pilares da educação digital. Pilar 2: gerenciamento da informação (2013). Acesso em: 12 jul. 2017.

DAVENPORT, Thomas H.; PRUSAK, Laurence. Conhecimento empresarial: como as organizações gerenciam o seu capital intelectual. São Paulo: Campus, 1998.

DAVIDOFF, Frank.; FLORANCE, Valerie. The informationist: A new health profession? Annals of Internal Medicine, v.132, n.12 p.996-998, 2000. Disponível em: http://annals.org/aim/article/713553/informationist-new-health-profession. Acesso em: 03 jul. 2017.

DE BIAGGI, C. Perspectivas e tendências da atuação do bibliotecário na área da saúde, 2017. 125p. Trabalho de conclusão de curso (Bacharelado em Biblioteconomia) Universidade Estadual Paulista (UNESP), Faculdade de Filosofia e Ciências, Marília, 2017.

FREIRE, Isa Maria. A responsabilidade social da Ciência da Informação e/ou olhar da consciência possível sobre o campo científico. 2001. Tese (Doutorado em Ciência da Informação). Convênio CNPq/IBICT - UFRJ/ECO, Rio de Janeiro, 2001.

LIPSCOMB, Carolyn E. Clinical librarianship (Historical notes). Bulletin of the Medical Library Association, v.88, n.4, p.393-395, Oct. 2000. Disponível em: https://www.ncbi.nlm.nih.gov/pmc/articles/PMC35263/. Acesso em: 12 jul. 2017.

MARCHIORI, Patricia Zeni. A ciência da gestão de informação: compatibilidades no espaço profissional. Ciência da Informação, Brasília, v.31, n.2, p.72-79, maio./ago. 2002. Disponível em: http://revista.ibict.br/ciinf/article/view/962/999. Acesso em: 10 ago. 2017.

MORAES. Ilara Hammerli Sozzi de.; GÓMEZ, Maria Nélida González de.Informação e informática em saúde: caleidoscópio contemporâneo da saúde. Ciência \& Saúde Coletiva, Rio de Janeiro, v. 12, n. 3, maio/jun. 2007. Disponível em: http://www.scielo.br/scielo.php?script=sci_arttext\&pid=S1413-81232007000300002. Acesso em: 5 ago. 2017.

OLIVEIRA, Marlene.; BERTUCCI, Maria da Graça Eulálio de Souza . A pequena e média empresa e a gestão da informação. Informação \& Sociedade: Estudos, João Pessoa, v.13, n.2, p.65-87, jul./dez. 2003. Disponível em: http://www.ies.ufpb.br/ojs2/index.php/ies/article/view/91/1558. Acesso em: 4 ago. 2017.

OLIVEIRA, Djalma de Pinho Rebouças de. Sistemas de informações gerenciais: estratégicas, táticas e operacionais. 9. ed São Paulo: Atlas, 2004.

PINOCHET, Luis Hernan Contreras.; LOPES, Aline de Souza.; SILVA, Jheniffer Sanches. Inovações e tendências aplicadas nas tecnologias de comunicação e informação na gestão da 


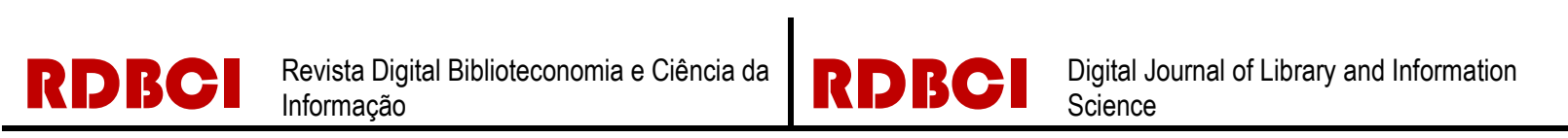

saúde. Revista de Gestão em Sistemas de Saúde, v.3, n.2, jul./dez. 2014. Disponível em: http://www.revistargss.org.br/ojs/index.php/rgss/article/view/88/0. Acesso em: 3 ago. 2017.

PLUTCHAK, T Scott. Informationists and librarians. Bulletin of the Medical Library Association, Chicago, v. 88, n. 4, p.391-392, oct. 2000. Disponível em:

https://www.ncbi.nlm.nih.gov/pmc/articles/PMC35262/. Acesso em: 2 jul. 2017.

PONJUÁN DANTE, Gloria. Gestión de información: dimensiones e implementación para el êxito organizacional. Gijón: Trea, 2007.

SERAFIM, Sonia Aparecida Dias. Impacto da Informatização na Dispensação de Medicamentos em um Hospital Universitário. 99 p. Dissertação (Mestrado em Saúde na Comunidade) - Faculdade de Medicina de Ribeirão Preto da Universidade de São Paulo, Ribeirão Preto, 2005.

SIMEÃO, Elmira.; MENDONÇA, Valéria. Comunicação da Informação em Saúde no Brasil: aspectos de qualidade e desafios. In: Congresso Ibero-Americano de Comunicação da Informação em Saúde (CIACIS), I., 2007, Brasília. Anais... Brasília: [s.n], 2007. p. 85-93.

TABOSA, Hamilton Rodrigues.; PAES, Denyse Maria Borges.; FERREIRA, Ana Lúcia Duarte.; SOUZA, Maria Naires Alves de. A gestão da informação no programa saúde na escola em Fortaleza-CE: impasses e alternativas. RACIn, João Pessoa, v.1, n.1, p.30-49, jan./jun. 2013. Disponível em: http://www.repositorio.ufc.br/handle/riufc/12258. Acesso em: 4 ago. 2017.

VALENTIM, Marta Lígia Pomim. Equipes multidisciplinares na gestão da informação e conhecimento. In.: BAPTISTA, Sofia Galvão.; MULLER, Suzana Pinheiro Machado. (Org.). Profissional da informação: o espaço de trabalho. Brasília: Thesaurus, 2004.

VALENTIM, Marta Lígia Pomim. Gestão da Informação e Gestão do Conhecimento em ambientes organizacionais: conceitos e compreensões. Tendências da Pesquisa Brasileira em Ciência da Informação, v. 1, n. 1, 2008. Disponível em:

http://inseer.ibict.br/ancib/index.php/tpbci/article/view/3/14. Acesso em: 2 ago. 2017. 